\title{
La Identidad Corporativa de los grupos multimedia privados españoles a través de sus webs: entre el Marketing 2.0 y 3.0
}

The Corporate Identity of Private Spanish Multimedia Groups Through their Webs: Between Marketing 2.0 and 3.0

Marta Rico Jerez

Universidad Complutense de Madrid mrico01@ucm.es
Rico Jerez, M. (2013). La Identidad Corporativa de los grupos multimedia privados españoles a través de sus webs: entre el Marketing 2.0 y 3.0. Revista Internacional de Investigación en Comunicación aDResearch ESIC. No 8 Vol 8. Segundo semestre, julio-diciembre 2013. Págs. 26 a 45 DOI: 10.7263/ADRESIC.008.002 


\section{Clasificación JEL: \\ M31 \\ Key words:}

identidad corporativa,

marketing 3.0,

marketing 2.0,

grupos multimedia

españoles
El objetivo de esta investigación es analizar la aplicación del marketing 2.0 y 3.0 en la identidad de los grupos multimedia privados españoles a través de sus webs corporativas. Para tal fin se han estudiado los portales de PRISA, Antena 3, Mediaset, Mediapro, Vocento, Promecal e Intereconomía. De este modo, se ha realizado una investigación cualitativa en la que se han empleado la descripción transversal, la correlación y la explicación. Así, en primer lugar, mediante parámetros como el perfil corporativo — misión, visión y valores—, las estrategias de marca, los tipos de comunicación — simbólica y conductual_- el posicionamiento y la estructura de las webs corporativas se ha descrito la identidad de cada grupo de comunicación en un momento concreto. Posteriormente, se han comparado los datos obtenidos.

Finalmente, se ha explicado cómo han influido dichos resultados en la aplicación del marketing 2.0 y 3.0 .

Las conclusiones a las que se han llegado son las siguientes:

- La combinación del marketing 2.0 y el marketing 3.0 es una constante en la identidad corporativa de los grupos multimedia privados españoles, tanto desde el punto de vista de su perfil como desde su comunicación empresarial.

- La aplicación del marketing 3.0 en el funcionamiento interno de los grupos multimedia comerciales españoles se encuentra en un estado incipiente.

- Los grupos multimedia privados españoles se basan en el marketing 3.0 para posicionarse.

- Los grupos multimedia privados españoles como entes corporativos no suelen utilizar las redes sociales para interactuar con sus públicos, sino que suelen emplear el correo electrónico o el teléfono. Sin embargo, sí recurren a ellas en sus diferentes unidades de negocio.

\section{ABSTRACT}

\section{JEL Classification:}

\section{M31}

\section{Palabras clave:}

corporate identity, marketing 3.0, marketing 2.0, Spanish multimedia groups
The objective of this research is to analyse the application of marketing 2.0 and 3.0 in the identity of the private Spanish multimedia groups through their corporate webs. To this end, the websites of PRISA, Antena 3, Mediaset, Mediapro, Vocento, Promecal and Intereconomía have been studied.

In this way, a qualitative research study has been carried out where transversal description, correlation and explanation have been used. Thus, firstly, through parameters such as the mission, vision and values- corporate profile, brand strategies and communication typessymbolic and behavioural, the positioning and structure of the corporate webs have represented the identity of each communication group at a given moment. Later, the data obtained has been compared.

Finally, the paper has explained how the said results have influenced the application of marketing 2.0 and 3.0 .

The conclusions reached are the following:

- The combination of marketing 2.0 and 3.0 is a constant in the corporate identity of private Spanish multimedia groups, from the point of view of both their profile and their business communication.

- The application of marketing 3.0 in the internal functioning of the commercial Spanish multimedia groups is in an emergent state.

- Private Spanish multimedia groups are based in marketing 3.0 to position themselves.

- Private Spanish multimedia groups as corporate bodies do not normally use social networks to interact with their public, rather they generally use e-mail or the telephone. Nevertheless, they do use them in other business units. 


\section{Marco teórico}

\section{La identidad corporativa de los grupos multimedia privados españoles: entre el Marketing 2.0 y el Marketing 3.0}

Un aspecto fundamental en toda empresa es la identidad corporativa, que consiste en "el conjunto de atributos, valores o características que la empresa asume como propios, y con los que la compañía se autoidentifica y autodiferencia de las demás" (Capriotti, 2004:65). Es lo que Ramírez, Sánchez y Quintero (2005:45-46) denominaron personalidad y que, según ellos, está basada en la misión, la visión y los valores de la organización.

La identidad corporativa se puede analizar desde diversos puntos de vista entre los que destacan el plano ético y el plano cultural. El primero incluye los valores propios de la organización y la concepción de su responsabilidad social con el entorno humano al que afecta su actividad; en cambio, el segundo está relacionado con el conjunto de creencias y valores que rigen la conducta de la empresa, cualquiera que sea su forma jurídica y la estructura de su propiedad (Villagra, 2002:145). Ambos planos tienen como funciones garantizar la autenticidad y determinar una pertenencia, lo que unido a la diversificación dará lugar a una diferenciación de la competencia.

Una vez explicado qué es la identidad corporativa es preciso matizar que ésta se proyecta a través de la imagen corporativa. Esto es, la imagen corporativa es "la percepción de las empresas que tienen sus audiencias", la cual "se forma como resultado acumulativo de todos los mensajes que emite la empresa" (Bassat, 2008:73-74). Estos mensajes deben comunicarse de forma eficaz con el respaldo de la empresa y con una coherencia con la misión y los objetivos de la compañía.

Por tanto, la imagen corporativa se genera en los receptores de acuerdo con unos elementos racionales, emocionales y conductuales que transmiten las organizaciones mediante una comunicación global (Galán, 2008).

De todos los elementos mencionados, en la gestión de la imagen corporativa es clave la conducta, pues es importante influir en la actitud de los usuarios/consumidores. Es aquí donde juega un papel fundamental el marketing, el cual consiste en concebir, planificar, ejecutar y controlar la elaboración, el precio, la distribución y la comunicación de una idea, de un bien o un servicio con el objeto de llevar a cabo intercambios mutuamente satisfactorios para la organización y los individuos (González y Ganaza, 2008:171).

Sin embargo, el marketing, desde su nacimiento hasta hoy ha evolucionado en función de los cambios empresariales. De este modo, sus puntos de atención han sido muy diferentes desde entonces. Se ha orientado hacia el productor, la venta, el cliente, el mercado, etc., dependiendo del momento empresarial.

Podemos hablar, por tanto, de una evolución del marketing 1.0 al marketing 3.0 (Kotler, Kartajaya, \& Setiawan, 2011:19-52). Así, al principio, el centro del marketing 1.0 eran las características físicas del producto y se debían atender las necesidades de un mercado de masas.

Posteriormente, como consecuencia de la irrupción de las Tecnologías de la Información y la Comunicación (TIC), nace el marketing 2.0 cuyo eje es el usuario/consumidor, al que se debe fidelizar, interactuando con él mediante herramientas como el correo electrónico. Por tal motivo, se utilizan tácticas como el posicionamien- 
to y se establecen factores como la misión, la visión y los valores corporativos para conseguir la diferenciación.

El más reciente es el marketing 3.0, donde la base son los valores y la apuesta por un mundo mejor mediante la interacción con varios consumidores a la vez a través de las redes sociales.

Concretamente, el marketing 3.0 es propiciado por el impacto de las TIC en las actitudes de los consumidores/usuarios y por la globalización, que han dado lugar a un panorama cultural, político-legal, económico y social interconectado en función de un mercado creativo que tiene "una visión más espiritual del mundo". De ahí que hayan adquirido relevancia el marketing de colaboración, el marketing cultural y el marketing horizontal. El primero de ellos consiste en la colaboración de una serie de entidades comerciales (accionistas, empleados, consumidores) con valores y objetivos similares; mientras que el segundo sitúa los aspectos culturales en el núcleo del modelo empresarial de una compañía mediante la marca cultural.

En cuanto al marketing horizontal, se fundamenta en la interacción con usuarios pertenecientes a sectores muy diferentes, pero que interactúan entre ellos.

En resumen, nos encontramos ante un modelo de negocio que gira alrededor de los valores corporativos y que requiere del marketing 3.0 para darlos a conocer.

\subsection{Misión Corporativa}

La misión corporativa "es la razón de ser de la empresa, lo que refleja el objetivo básico de la existencia de la empresa" (Kotler, Kartajaya y Setiawan, 2011:58-81). Según estos autores para llevar a cabo la misión es necesa ria la participación de los consumidores, en cuya conducta se debe in- fluir mediante la aplicación del marketing 3.0. De esta manera, no solo se conseguirá un impacto en el mercado de masas, sino que, además, los consumidores aceptarán la marca como parte de su vida diaria, que es en lo que consiste este marketing espiritual o del alma.

Concretamente en los grupos multimedia privados españoles, la misión que recogen sus webs corporativas son las siguientes:

- Grupo PRISA: Creación y distribución de contenidos culturales, educativos, de información y entretenimiento en los mercados de habla española y portuguesa, gracias a su oferta multicanal de productos de máxima calidad orientados al consumidor. (www. prisa.com).

- Grupo Antena 3: Difusión de una oferta atractiva, plural e independiente, que combine la información y el entretenimiento, para transformar así este valor en ingresos publicitarios (www.grupoantena3.com).

- Grupo Mediaset España: Conjunto de empresas dedicadas al desarrollo de negocios vinculados con el sector audiovisual. La línea principal de actividad del Grupo es la explotación del espacio publicitario de las cadenas de televisión que opera (www.telecinco.es/inversores/es/).

- Grupo Mediapro: Proveedor de servicios técnicos para la industria audiovisual, es productor y distribuidor de acontecimientos deportivos, productor cinematográfico y de contenidos interactivos, y presta servicios de postproducción. La ingeniería técnica, los servicios de trasmisiones, la consultoría en marketing y comunicación, y la comercialización publicitaria, así como el 
diseño y la producción de canales temáticos (www.mediapro.es/esp/index.php).

- Grupo Vocento: Tiene presencia destacada en todas las áreas de la información y el entretenimiento, como prensa, suplementos, revistas, televisión, radio, producción audiovisual, distribución cinematográfica e Internet (www.vocento.com).

- Unidad Editorial: Dispone de medios de difusión, que proporcionan información y entretenimiento a miles de hogares de todo el planeta, gracias al aprovechamiento de las nuevas tecnologías de la información (www.unidadeditorial.com).

- Grupo Promecal: Especialización en información regional y servicios multimedia (www.promecal.es).

- Grupo Intereconomía: es un grupo de comunicación multimedia, con actividades en los sectores de televisión, radio, internet, publicaciones, cine, formación y editorial (www.intereconomiaformacion.com).

Por tanto, en líneas generales, podemos decir que todos los grupos multimedia privados españoles tienen como misión principal informar, función que muchos complementan con el entretenimiento. Algunos de ellos, como Antena 3 y Mediaset España también resaltan su actividad publicitaria, en el caso del primero con referencia explícita a su finalidad económica.

Por lo dicho hasta el momento, el marketing que se aplica es el 1.0, pero con connotaciones del 2.0. El objetivo es vender su actividad, aunque con diferentes matices, ya que si todos se centran en la información, unos se dedican también a la publicidad, otros se especializan en los contenidos regionales, o en los deportes, por poner unos ejemplos.

\subsection{Visión Corporativa}

La visión corporativa consiste en establecer en qué aspira a convertirse la compañía y los logros que pretende alcanzar (Kotler, Kartjaya, y Setiawan, 2011, 58-59). Para ello es imprescindible tener en cuenta la misión corporativa. En palabras de Capriotti (2004:66), es "la perspectiva de futuro de la compañía, el objetivo final de la entidad”.

En los últimos años este concepto está muy vinculado a las Tecnologías de la Información y la Comunicación (TIC), ya que éstas han originado importantes cambios empresariales (De Pablo y col., 2012:80). De esta manera, en los años 80 el objetivo era "acelerar el procesamiento de datos y las transacciones de los procesos de generación valor, dándole especial importancia a las bases de datos y a la integración de sistemas y procedimientos de información".

Años más tarde, en los 90, "con el nacimiento de internet, tecnología y empresa evolucionan conjuntamente dando más peso a las redes y el procesamiento distribuido como soportes del crecimiento y por efecto de la globalización".

En el siglo XXI, el desarrollo de las tecnologías de información y las comunicaciones (web 2.0, redes sociales, comunicaciones móviles, etc.) no solo está cambiando el contexto económico, sino también el social convirtiendo a la información en motor impulsor de cambios sociales y culturales que afectan al modo en el que se realizan las transacciones económicas y a las que las organizaciones no pueden ser ajenos.

Claros ejemplos de estos hechos se encuentran en la visión corporativa de los siguientes grupos multimedia privados de España:

- En Prisa, como se recoge en el Informe Anual de 2011, el objetivo es "generar bienestar cultural en el mundo, como pilar para garantizar el progreso económico y 
social, y sostenible, y la participación en una sociedad global" (www.prisa.com).

- En Antena 3, la finalidad es "ser un grupo de comunicación multimedia, rentable e independiente, líder en calidad, que sea referencia en el mercado español e internacional, con capacidad de anticiparse a las expectativas y los deseos de su audiencia y de mantener así un atractivo potencial sólido y diversificado para los distintos agentes del mercado publicitario" (www. grupoantena3.com).

- Mediaset España, según el acta de su Junta General de Accionistas de marzo de 2012, apuesta por la "creación de una sede electrónica de la Sociedad", es decir, pretende poner en marcha una web corporativa de la Sociedad con la dirección www.telecinco.es (www.telecinco.es/inversores/es/).

- Unidad Editorial se proyecta como un grupo dispuesto a explorar todas las plataformas que les acerquen a quienes quieran informarse, formarse o entretenerse a través de nuestros medios, siempre con el denominador común de la calidad de los contenidos (www.unidadeditorial.com).

Sin embargo, esta tendencia no se refleja en todos los grupos de comunicación. Es el caso de Vocento y Promecal:

- Vocento se sitúa de cara al futuro como uno de los actores principales para liderar el sector de los medios de comunicación en España mediante el fortalecimiento de su mercado nacional y la mejora de su posición en los medios locales (www.vocento. com).

- Para Promecal, lo importante es lograr la mejor integración de recursos atendiendo a las necesidades de cada zona geográfica mediante el refuerzo de su estructura directiva tanto de sus medios escritos de Valladolid como de Castilla-La Mancha (www.promecal.es).

Otras organizaciones como Mediapro o Intereconomía no incluyen sus objetivos en sus webs corporativas.

Según lo planteado, la principal tendencia de los grupos de comunicación españoles es la consolidación de las Tecnologías de la Comunicación y la Información a través de internet y de los formatos multimedia, ya sea para hacer un mundo mejor — como PRISA—, ya sea para satisfacer las necesidades de los usuarios — como Antena 3-. Esto es, se puede apreciar la aplicación tanto del marketing 2.0 como del marketing 3.0 .

\subsection{Valores Corporativos}

En el apartado anterior hemos visto como PRISA tiene una visión basada en valores, pero éstos se incluyen también en el resto de los grupos, porque en el siglo XXI los valores corporativos se han convertido en el centro de la gestión empresarial.

Sin embargo, ¿qué entendemos por valores? Son varias las definiciones que se pueden dar al respecto:

- Son conceptos básicos o finalistas que la compañía asume como institución, en relación con su entorno social, cultural, económico, etc., con la intención de generar credibilidad y confianza (ética corporativa, responsabilidad social, cuidado del medio ambiente, etc) (Capriotti, 2004:67-68).

- Son convicciones básicas sobre lo que es correcto y cierto, sobre lo que se debe y no se debe hacer y sobre la importancia que 
tienen distintas cosas dentro de la empresa. Son el elemento fundamental de la cultura y marcan una dirección común para todos los empleados (marcan pautas de conducta), con lo que facilitan la labor de los directivos. Las personas traen a la empresa sus propios valores, y otros están presentes en el conjunto de la sociedad, pero aquí nos referimos solo al grupo de valores que son aceptados y compartidos por los miembros de la empresa como tales (González y Ganaza, 2008, 550-551).

- Se pueden considerar como los estándares institucionales de conducta dentro de la compañía. Como todas las empresas suelen seguir por lo general el mismo ciclo de valores, éstos se simbolizan con una rueda. Los valores articulan una serie de prioridades corporativas y criterios de gestión para integrarlos como parte de sus prácticas, con la esperanza de reforzar las conductas que beneficien a la compañía y a las comunidades dentro y fuera de ella, lo que a su vez fortalecería los valores de la institución (Kotler, Kartajaya y Setiawan, 2011:59).

En estas definiciones se puede apreciar cómo los valores corporativos han evolucionado hacia unos consumidores cada vez más personalizados, que cobran un papel protagonista y a los que es necesario dirigirse a través de medios no convencionales (Ramírez, Sánchez y Quintero, 2005:37-42).

Por tanto, los valores corporativos se pueden clasificar atendiendo a la relación con la misión y la visión:

- Finales o terminales. Aquéllos que el individuo desea lograr a lo largo de su vida. Están relacionados con la misión y entre ellos caben destacar: los valores personales (éxito, felicidad, trabajo, realización personal, entre otros) y valores ético-sociales (justicia social, supervivencia del planeta entre otros).

- Instrumentales. Aquéllos que implementa mediante la conducta para lograr los valores terminales. Están relacionados con la visión y entre ellos se incluyen: los valores ético-morales (honestidad, responsabilidad, solidaridad, confianza, cooperación, entre otros) y los valores de competencia (cultura, flexibilidad, dinero, lógica, iniciativa, entre otros).

Todos estos valores corporativos se fundamentan en la ética empresarial, que consiste en la reflexión necesaria e imperativa sobre valores, normas, costumbres y experiencias que ocurren en el entorno organizacional, a tenor con la realidad en que se desempeña la misma (Pérez, 2010:157-248).

En otras palabras, las empresas se enfrentan a demandas de grupos de interés externos (como consumidores, competencia, agencias gubernamentales, organizaciones no gubernamentales, etc.), así como de grupos de interés internos (como trabajadores y accionistas), que esperan de ellas un comportamiento moral y nuevas actitudes y compromisos para con la sociedad.

Pero, antes de llegar a esta necesidad, la ética empresarial "se circunscribía a cumplir con normas legales y regulaciones internacionales", a la vez que las organizaciones se "limitaban a seguir ciertos manuales que definían lo que podían o no hacer los empleados". En cambio, actualmente, otro foco de atención son "los reclamos y necesidades de sus grupos de interés".

Por tales circunstancias, para poner en práctica sus valores corporativos, las empresas recu- 
rren a dos tácticas, el código de conducta y las acciones producto de la responsabilidad social.

Los códigos de conducta recopilan los principios y pautas de comportamiento de los empleados.

Entre los grupos multimedia aquí analizados cabe destacar que solo PRISA y Antena 3 hacen públicos sus códigos de conducta a través de su web corporativa, mientras que Intereconomía únicamente expone sus principios rectores mediante su Ideario.

En PRISA (www.prisa.com), el código de conducta que está en vigor, fue modificado en diciembre de 2011 y, desde entonces, el comportamiento de las personas que forman parte de esta organización se debe regir por:

- Integridad, honradez, rigor y dedicación en el ejercicio de su actividad.

- Responsabilidad, compromiso y transparencia.

- Pluralismo y respeto a todas las ideas, culturas y personas.

- Creatividad e innovación en el desarrollo del negocio.

- Gestión responsable, eficiente y sostenible, generadora de valor para el accionista y para la sociedad.

En lo que se refiere a Antena 3 (www.grupoantena3.com), es tanta la importancia que tiene el Código de Conducta que existe un Comité de Cumplimiento del mismo, siendo las pautas para los empleados las siguientes:

- Respeto entre las personas.

- Desarrollo profesional, igualdad de oportunidades y no discriminación.

- Trabajo en equipo, colaboración y dedicación.

- La seguridad y la salud de las personas.
El Ideario de Intereconomía (www.intereconomiaformacion.com) recoge todos los principios que deben tener en cuenta todos los integrantes de este grupo de comunicación:

- El deber y derecho de atenerse a criterios de verdad, libertad y calidad profesional en la comunicación de información y contenidos.

- El compromiso con la dignidad innata e inviolable de cada persona humana y con el respeto efectivo a sus derechos y libertades fundamentales en el marco de una sociedad libre, justa, solidaria y democrática.

- La identificación con las raíces cristianas de la civilización bajo el prisma del pensamiento humanista.

- La independencia de todo partido político, confesión e institución religiosa, y de cualquier organización de poder ideológico, económico o social. El sentido de esta independencia es el servicio al derecho de información de sus lectores, oyentes y televidentes por encima de cualquier servidumbre.

- Considerar que la identidad y unidad de España son una realidad histórica, un bien común y un patrimonio vivo, transmitido entre generaciones, cuyas formas de configuración pertenecen en exclusiva a la soberanía de todos los españoles.

- Compromiso con la libertad de las personas y de la sociedad civil, y apoyo a la libre iniciativa privada y al modelo social y económico que, puesto al servicio de las personas, de la justicia, de la solidaridad y del bien común, configura el Estado social y democrático de Derecho.

- Defensa del derecho a la información veraz, la prensa libre y la independencia de los 
jueces, sin las cuales la falsedad, la arbitrariedad y el abuso de poder pueden desnaturalizar las instituciones y menoscabar impunemente aquella verdad, libertad, confianza cívica, igualdad y garantía de los ciudadanos ante la ley, que son imprescindibles para que la democracia y el Estado de Derecho sean auténticos.

- Considerar la familia un bien común de la entera sociedad por ser la comunidad natural, más originaria e íntima, donde la procreación, crianza y educación de los hijos se asegura desde la unión conyugal de los padres y mediante una genealogía entre personas, que la dotan de un singular potencial para impregnar de afectos amorosos, valores humanos básicos, responsabilidad y solidaridad incondicionales los lazos de parentesco, los vínculos entre generaciones, la maduración de las personalidades y la integración de la juventud en la sociedad.

- Reconocer a los padres el derecho innato e inalienable a la educación de sus hijos y la titularidad primera en el proceso de su ejercicio efectivo en el sistema educativo. En consecuencia, Intereconomía promoverá la libertad de enseñanza y pondrá sus medios al servicio de la defensa y el desarrollo de los derechos de los padres a elegir libremente para sus hijos la educación y el centro académico conforme a sus convicciones morales y religiosas.

- Comunicar una información verdadera, rigurosa y coherente en la acreditación de los hechos y la argumentación de las opiniones, respetuosa con las personas e instituciones, con sus bienes y derechos, al tiempo que desea contribuir a desterrar cualquier forma de engaño, mentira, falsedad y manipulación de la vida social y, en especial, de la política.

- Considerar que su servicio a la información veraz y su lucha contra la mentira tienen sentido porque existe la verdad objetiva, hay deber de buscarla y es posible conocerla y comunicarla en aquella satisfactoria medida que garantizan la honradez, la capacidad y el rigor profesionales puestos en los métodos y fines. En este servicio, todos los medios de Intereconomía, además de distinguir la información de la opinión, se esforzarán para que la información sea completa, actual, independiente, objetiva y acreditada.

- Fomentar en sus medios la mejor y más actualizada información científica, pero evitando calificar como verdad científica lo que no lo sea o acreditar con valor absoluto lo que la propia ciencia considere provisional o discutible, y eludiendo extrapolar el natural ámbito y límites de la racionalidad y métodos científicos de modo que se impusieran simplificaciones y arbitrariedades a las legítimas convicciones, creencias y libertades de nuestros usuarios.

- Velar para que las informaciones y los contenidos ofrecidos en sus medios sean servidos por profesionales veraces y responsables con la capacidad idónea y la formación necesaria en sus cometidos.

- Respeto a la intimidad personal y familiar, así como la defensa de los derechos al honor y buena fama.

Por lo expuesto hasta el momento sobre ética empresarial, podemos afirmar que hay una heterogeneidad en los principios y las pautas a seguir, 
así como que en los medios de comunicación españoles se vislumbra una tendencia hacia un mundo mejor, pues se considera al ser humano como un ente integral y se valora el trabajo en equipo. Esto es, se empieza a utilizar el marketing 3.0 en la gestión interna de los grupos multimedia.

Por otra parte, en lo que respecta a la Responsabilidad Social Corporativa, es el "conjunto de obligaciones legales (nacionales e internacionales) y éticas de la empresa como consecuencia de la relación con sus grupos de interés y del desarrollo de su actividad de la que se derivan impactos en el ámbito social, medioambiental, laboral y de derechos humanos en un contexto global" (Galindo y Fernández, 2007:112-113). Estas obligaciones son adquiridas por las compañías de acuerdo con dos premisas:

- La Responsabilidad Social Corporativa es una contribución activa y voluntaria de las empresas al mejoramiento social, económico y ambiental con el objetivo de mejorar su situación competitiva y su valor añadido.

- La Responsabilidad Social Corporativa es una obligación que las empresas observan para considerar los intereses de clientes, empleados, accionistas, comunidades y ecología en todos los aspectos de sus operaciones (Polo, 2009:80).

Como indica Marín Calahorro (2008:14-26), la sociedad valora las actividades empresariales dirigidas a mejorar la calidad de vida, a apoyar el desarrollo comunitario, el fomento de la cultura y la investigación, la protección del patrimonio histórico, la promoción de acontecimientos deportivos y otros de interés general, que pueden favorecer el bienestar social, ya que las empresas son concebidas como entes sociales, que deben colaborar con la comunidad en la que se desa- rrollan sus actividades. Por tal motivo, la Organización de Naciones Unidas (ONU), así como la Unión Europea y la Organización Internacional del Trabajo (OTI), entre otras, promueven iniciativas y acciones que fomenten la Responsabilidad Social Corporativa. Concretamente al programa de la ONU se han adherido PRISA, Antena 3 y Mediaset.

Desde el punto de vista de los receptores, estas actividades empresariales se percibirán como una imagen corporativa positiva, lo que ha supuesto su incorporación a las organizaciones como una labor más. Es el caso de los grupos multimedia privados españoles, la Responsabilidad Social Corporativa se refleja de la siguiente manera en sus webs corporativas:

- PRISA asume como propio el papel de ser referente en materia de responsabilidad corporativa frente a sus empleados, accionistas, clientes, proveedores, el entorno y la sociedad en su conjunto. Por tanto, actúa como promotor y defensor de los valores sociales y culturales en las regiones donde desarrolla sus actividades, mediante la promoción de la cultura y las artes, el fomento de la educación, la escuela de periodismo, la acción social y el medioambiente (www. prisa.com).

- Antena 3 ha asumido el compromiso y la responsabilidad de poner al servicio de la sociedad la capacidad de difusión de sus medios de comunicación, incidiendo en un tratamiento responsable de los contenidos y las comunicaciones comerciales, así como en la accesibilidad y la transparencia. La imparcialidad, la libertad de expresión, la pluralidad y la protección a los grupos más vulnerables son también principios que guían su actividad. 
Como empresa responsable y sostenible, trata de dar respuestas a las expectativas de sus grupos de interés, que se centran en el ejercicio de una comunicación responsable, en la atracción y retención del talento, en seguir a la vanguardia del desarrollo digital, en la adecuada gestión de las audiencias, y en la protección del medio ambiente (www.grupoantena3.com).

- Mediaset llevó a cabo una investigación sobre qué asuntos eran considerados relevantes para sus grupos de interés y, desde entonces, sus actividades se centran en la protección de la infancia y la adolescencia en los contenidos emitidos, el reflejo de la diversidad social y cultural en la programación, la emisión responsable de publicidad, el fomento de la educación y la cultura a través de los contenidos emitidos, la sensibilización sobre los retos de la sostenibilidad, la gestión responsable de los recursos humanos, la transparencia, la gestión de los impactos ambientales, la rendición de cuentas, el apoyo a la comunidad y el diálogo con grupos de interés (www.telecinco.es/inversores/es).

- Vocento ejerce sus acciones de responsabilidad social corporativa a través de la Fundación del mismo nombre y centra sus actividades en las áreas culturales, donde destacan las Aulas de Cultura, los Máster de Periodismo y el Noticiero de las Ideas, la revista digital de pensamiento donde se dan cita algunas de las firmas más prestigiosas del panorama intelectual español. También participa en los Cursos de la Universidad Internacional Menéndez Pelayo y de la Universidad de Cádiz, y patrocina los cursos de verano de la Universidad de Cantabria en Laredo (www.vocento.com).

- Promecal en su vocación de servicio al ciudadano y consciente del papel que desempeñan las empresas de comunicación en la sociedad, se marca como objetivo permanente impulsar sus acciones relacionadas con la Responsabilidad Social Corporativa. Por ello, tiene como objetivo concienciar a los lectores y espectadores en distintas materias de índole cultural, sanitaria, social, medioambiental y solidaria. Para tal fin, no solo es parte colaboradora y sujeto activo en actos y campañas solidarias, sino que también cubre acontecimientos en los que los valores sociales son los protagonistas (www.promecal.es).

- Unidad Editorial centra su Responsabilidad Social Corporativa en la creación de valor para los accionistas, el crecimiento cultural del país, la conciencia de trabajar como un grupo, la valorización de las personas, la integridad y el rigor, la claridad y la transparencia, la eficiencia, la eficacia, la satisfacción de los clientes (www.unidadeditorial.com).

- Intereconomía plantea la promoción de lugares de encuentro con otras culturas e ideologías, sobre valores de la moral y el derecho natural; facilita el mejor conocimiento de los bienes de la cultura, de las ciencias y las artes, y declara un compromiso preferente hacia los mayores, minusválidos y cuantos, por circunstancias desfavorables, merezcan amparo y solidaridad, con mención especial hacia las víctimas del terrorismo y quienes, en cumplimiento de sus deberes, murieron por España (www.intereconomiaformacion.com). 
En resumen, la Responsabilidad Social Corporativa se considera un tema relevante en los grupos multimedia comerciales españoles, ya que, excepto Mediapro, todas las compañías analizadas la dan a conocer en sus portales. Incluso, algunos de ellos como PRISA, Antena 3 o Mediaset se han adherido a programas de carácter internacional como es el Pacto Global de la ONU.

En cuanto a las acciones, sus objetivos son dos, uno satisfacer las necesidades de sus públicos, y otro, hacer un mundo mejor. Por ello, realizan, por orden de relevancia, acciones culturales, sobre medio ambiente y solidarias.

En otras palabras, se aplica una combinación del marketing 2.0 con el marketing 3.0.

\section{La aplicación del Marketing $\mathbf{2 . 0}$ y 3.0 en la comunicación de la identidad corporativa de los grupos multimedia comercia- les españoles}

La comunicación es una herramienta imprescindible para que la identidad corporativa llegue a influir en la conducta de los públicos. Pero, "en una compañía, no solo comunican los anuncios publicitarios o las campañas de relaciones públicas, sino también toda la actividad cotidiana de la empresa, desde sus productos y servicios hasta el comportamiento de sus miembros" (Capriotti, 2004:68). De ahí la importancia que está adquiriendo la ética empresarial, de la que hemos hablado en los párrafos precedentes.

Tradicionalmente, los objetivos de la comunicación han sido: "crear conocimiento de los productos de la empresa, dar información para reducir la incertidumbre (riesgo) en la compra, inducir a la prueba de los productos, mantener la lealtad de los clientes e informar sobre las acciones de la empresa para mantener su ima- gen" (Domínguez y Ganaza, 2008:200). De todos ellos, el último se está convirtiendo en prioritario.

Como dice Bassat (2008:75-76), "la comunicación corporativa constituye el proceso que convierte la identidad de una empresa en su imagen pública. Todos los mensajes que emite la empresa nos han de llevar coherentemente hacia el mismo objetivo estratégico". Es lo que se conoce como imagen corporativa.

La imagen corporativa se ha convertido en la piedra angular de todo el proceso comunicacional de empresas e instituciones. Todo proceso de comunicación corporativa se inicia porque se quiere generar una determinada imagen corporativa: de una empresa, de un producto, de una marca, de una persona, etc. (Galán, 2008)

Esta nueva situación tiene su origen en que las empresas, debido a las TIC se han encontrado en un entorno competitivo diferente, por lo que se han visto obligadas a modificar su gestión empresarial y, por ende, el enfoque de su comunicación corporativa. Lo importante es dar a conocer unos valores intangibles que se identifican con la compañía y determinan el valor de la marca (Villagra, 2002:343-345).

Antes los consumidores aspiraban a la marca y a los valores que van asociados a ella; en cambio con la reestructuración empresarial son las marcas las que deben aspirar a los valores de los consumidores (Bassat, 2008:124). Los clientes demandan a las empresas que contribuyan a proteger la sociedad.

Estas exigencias por parte de los públicos unidas a las TIC han suscitado que, actualmente, para lograr el objetivo marcado se pueden llevar a cabo tres estrategias comunicacionales. Son las siguientes: 
- La comunicación directa, que consiste en utilizar sus webs para estar en contacto con sus públicos.

- La comunicación bidireccional, que consiste en estar presente en las webs de otras compañías.

- La comunicación compartida, que consiste en interactuar con los públicos mediante las redes sociales.

\subsection{Tipos de comunicación corporativa}

Además de las estrategias que acabamos de mencionar, en la comunicación corporativa se emplean la comunicación "simbólica" y la comunicación "conducta".

\subsubsection{La comunicación "simbólica" y el Marketing 2.0.}

La comunicación "simbólica" es una de las formas comunicativas que suelen aplicar las organizaciones y consiste en dar a conocer lo que éstas hacen. En otras palabras, "es el conjunto de mensajes y acciones de comunicación elaborados de forma voluntaria para ser transmitidos a los públicos de la firma, con el fin de informarlos sobre sus opiniones, actitudes y conductas hacia la compañía" (Capriotti, 2004:69).

Se trata de un modelo de comunicación lineal que informa a sus públicos objetivos sobre sus productos o servicios, pero no establece ninguna relación con ellos porque se basa en la generación y el envío unidireccional de información de la entidad (notas y ruedas de prensa, campañas de publicidad) con poco o casi ningún tipo de participación del público receptor de sus mensajes corporativos (Celaya, 2011:89).

A pesar de no interactuar con el público, se trata de una estrategia que genera expectativas y para lo que las empresas pueden recurrir a diferentes tipos de discursos:

- El de identidad, que comprende toda la comunicación propia de los códigos permanentes de la existencia y de la identificación de empresas y organizaciones. Son las acciones definidas en el llamado manual de identidad corporativa, que engloba todos los sistemas de identidad visual de todos los soportes de comunicación existentes: códigos tipográficos, de logotipos, de emblemas, de colores y otros. Es la imagen visual de empresas y organizaciones.

- El de la personalidad, que comprende las comunicaciones realizadas a través de la marca, la expresión de la imagen de marca, como algo simbólico y representativo.

- El de los hechos, que comprende la comunicación a través de productos y servicios, por medio de la realidad tangible que produce una empresa u organización. Las acciones de diseño de los productos, las técnicas del envasado, la comunicación de las ventajas y los beneficios, están aquí comprendidos, como también lo están las acciones de promoción y merchandising.

- El cultural, propio de la llamada comunicación institucional, que consiste en la transmisión de valores y roles que cada empresa desea intercambiar con su entorno.

De todos estos tipos de discurso, el utilizado por los grupos multimedia privados es el cultural, como se puede observar en la visión corporativa comentada en el apartado correspondiente. En el mismo epígrafe también se puede comprobar que la comunicación "simbólica" es el modelo comunicacional por excelencia. Tales circunstan- 
cias nos permiten aseverar que, en su comunicación corporativa, aplican el marketing 2.0.

\subsubsection{Comunicación conductual: la com- binación del Marketing 2.0 con el Marketing 3.0.}

La comunicación conductual "es la que genera información mediante la experiencia de los públicos con la compañía (con sus productos y/o servicios, y con las personas que pertenecen a la misma)" (Capriotti, 2004:70). Por ello, es fundamental que la empresa transmita los valores y principios con los que se identifica que son las variables de identidad de marca presentes en la imagen corporativa.

Las empresas incorporan en sus estrategias de gestión aspectos ligados a su responsabilidad social, destinando recursos y gestionándolos con el objetivo de mejorar su impacto y percepción en la sociedad y en el mercado (Galindo y Fernández, 2007:104).

Entre las entidades que utilizan esta forma de comunicación están los grupos multimedia privados españoles aquí estudiados. Excepto Mediapro, todos los demás dedican parte de sus esfuerzos a influir en el comportamiento de sus públicos a través de las acciones de su Responsabilidad Social Corporativa, como hemos visto en el apartado correspondiente.

Por tanto, del mismo modo que comentamos en el epígrafe 1.3, la aplicación del marketing 2.0 combinado con el marketing 3.0 es una evidencia.

\subsection{La marca y el Marketing 3.0 en los grupos de comunicación multimedia privados españoles}

La marca es una herramienta básica en todo proceso de comunicación de la identidad corporativa. Pero, ¿qué entendemos por marca?
La marca es "una señal que se hace, se añade, o se inscribe de modo imborrable en la materialidad misma de un producto para distinguirlo, hacerlo reconocer y recordar. En el mercado libre de concurrencia, una marca (de identidad, de propiedad, de fábrica, de producto o servicio) es siempre un elemento semántico o semiótico que cristaliza en un signo visual y fónico (una figura icónica y un sonido verbal)" (San Nicolás, 2004:352).

La marca siempre ha estado muy vinculada a la identidad corporativa. Dicha unión fue propiciada, en un primer momento, por la segunda revolución industrial y como consecuencia de la producción seriada y masiva.

Con el paso de los años, esta relación se ha modificado por los cambios empresariales y por los intereses de los públicos (Villagra, 2002:171172), porque ahora:

- La marca está ligada al valor de la empresa, su misión, los productos y servicios que ofrece y los públicos objetivos a los que se dirige.

- Las marcas no son los logotipos sino sus servicios.

- La marca es el valor central integrador de la empresa.

- La marca es un activo intangible en cuya construcción es decisivo el comportamiento de la empresa.

Las principales ventajas de utilizar una marca son la diferenciación de la competencia y la generación de confianza en el público.

La diferenciación, junto con la marca, el posicionamiento y el modelo $3 i$ (identidad, integridad e imagen), es un elemento esencial en el marketing 3.0. Elementos entre los que debe existir un 
equilibrio (Kotler, Kartajaya y Setiawan, 2011:5263).

Una diferenciación en sinergia con el posicionamiento generará automáticamente una buena imagen de marca. A su vez, el posicionamiento influirá en la conducta de los públicos, porque la identidad de marca consiste en posicionar una marca en la mente de los consumidores.

A todo esto se suman la integridad de marca, que consiste en cumplir lo que se ofrece a través del posicionamiento y la diferenciación de la marca, y la imagen de marca, que consiste en captar una parte importante de las emociones de los consumidores.

Por todo lo dicho, si se define claramente la identidad, a la vez que se la fortalece con una única integridad para construir una imagen de marca fuerte y para recuperar la confianza de los consumidores, se habla del marketing 3.0 integrado en la misión, visión y valores de la empresa.

\subsubsection{El Marketing 2.0 y la estrategia de marca en los grupos de comunicación multimedia privados españoles}

La elección de la marca está en función de los objetivos que se pretendan conseguir, los cuales, a su vez, van a determinar la estrategia más adecuada para el posicionamiento que se desee obtener. Las posibles estrategias (González y Ganaza, 2008:183-184) para utilizar son las que a continuación se detallan:

- Marca única: consiste en anteponer el nombre genérico del producto a la marca elegida. Con esta estrategia se facilita la introducción de nuevos productos y se abaratan los costes de distribución y promoción.

- Marca individual, o múltiples marcas: cada producto lleva una marca distinta. Se suele aplicar a productos muy distintos en calidad, distribución y mercado. Por un lado, el hipotético fracaso de un producto no afecta al resto, por otra parte, dar a conocer cada producto requiere un elevado gasto.

- Marca por línea de productos: es una estrategia intermedia entre las anteriores. Busca la potenciación mutua entre los productos de una línea.

- Marca de empresa fabricante: se utiliza para apoyar al producto, que posee su marca, con el nombre de la empresa, si esta goza de un reconocido prestigio.

- Marca del distribuidor: se emplea para productos escasamente diferenciados o debido a la debilidad de posición ante el distribuidor, que es quien aporta su nombre al producto.

De todas estas estrategias, los grupos multimedia analizados recurren a varias de ellas, siendo la de marca individual, o múltiples marcas, la principal opción. Esto se debe a su objetivo de aumentar sus cuotas de mercado a través de una diversificación en la que abarcan diferentes áreas de negocio:

- PRISA estructura su actividad en educación-editorial, prensa, radio y audiovisual.

- Antena 3 comprende publicidad, relaciones públicas, multimedia, cine y radio.

- Mediaset se dedica a la televisión y a la publicidad.

- Mediapro se estructura en contenidos, producción y postproducción, gestión de derechos, ingeniería audiovisual, canales tv, $\mathrm{I}+\mathrm{D}$, marketing.

- Vocento se organiza en prensa, suplementos, revistas, televisión, radio, internet, con- 
tenidos, impresión, difusión, prensa gratuita.

- Unidad Editorial se divide en el mundo, marca, expansión, televisión, revistas, salud, formación, distribución, editorial.

- Promecal divide su actividad en televisión y radio, prensa, servicios y multimedia.

- Intereconomía se diversifica en radio, televisión, internet, publicaciones, formación, editorial.

La estrategia de marca individual en algunos grupos se combina con la marca única. Así, por ejemplo en PRISA están El País y elpais.com; en Antena 3, Antena 3 Nova y Antena 3 Neox; en Mediapro, GolTv y golstadium.com, y en Intereconomía, Radio Intereconomía e Intereconomía TV.

Por último, en cuanto al Grupo Antena 3 es resaltable el uso de la marca de empresa pues se estructura en Antena 3 Eventos, Antena 3 Advertising, Antena 3 Multimedia, Antena 3 Films y Antena 3 TV. Solo la unidad de negocio de radio, Uniprex, no incluye el nombre de la compañía.

Con estas estrategias de marca, los grupos multimedia privados españoles pretenden satisfacer y retener a sus diferentes públicos para incrementar sus cuotas de mercado en todas sus áreas de negocio. Por tal motivo, tienen que aplicar las técnicas propias del marketing 2.0.

\subsubsection{El posicionamiento como función de marca: entre el Marketing 2.0 y el marketing 3.}

La selección de la estrategia de marca, además de depender de los objetivos empresariales, se establece atendiendo a varias funciones comunicativas: de referencia, de practicidad, de garantía, de personalización, de posicionamiento, lúdica y de capitalización. De todas ellas, actualmente, por la fase 3.0 en la que se encuentra el marketing, la función más determinante es el posicionamiento que designa el lugar que los mensajes tienen en la mente de los públicos, establecido por las percepciones previamente existentes.

Posicionar requiere unas estrategias de comunicación que se llevan a cabo en las siguientes etapas:

1. La empresa realiza un estudio de mercado.

2. La empresa decide el posicionamiento de un producto en función de sus características o atributos, que le diferencian y distinguen de sus competidores.

3. Una vez obtenidos los resultados se realiza un plan de comunicación dirigido a obtener un posicionamiento concreto y no otro, estableciendo unos objetivos de comunicación

4. Por último, se elabora una campaña comunicativa, utilizando todos los medios propios de la comunicación global, elaborando y transmitiendo unos mensajes interesados, adecuados a los objetivos planteados.

Sin embargo, si se pretende un posicionamiento satisfactorio, las acciones comunicativas se deben enfocar hacia uno o más factores como son: las características objetivas, los beneficios obtenidos, los usos y las aplicaciones, la diferenciación, la competencia o el consumidor.

El posicionamiento tiene su origen en el entorno competitivo en el que se encuentra el mundo empresarial, donde las compañías deben poseer una serie de atributos para ganar clientes/ usuarios y lograr su fidelidad (Capriotti, 2004:68). Esos atributos, también conocidos como "de marca", deben ser percibidos como gratificantes 
a la hora de satisfacer las necesidades de los públicos, tanto desde el punto de vista cognoscitivo, como desde la perspectiva emocional, como desde el comportamiento.

Los atributos de marca se pueden clasificar en primarios y de valor añadido. Los primeros son aquéllos que la marca procura en primer lugar, con una utilidad manifiesta y explícita, que dan lugar al beneficio básico. En los grupos multimedia privados españoles, el atributo es la información, excepto en Mediapro que es el entretenimiento.

En cuanto a los de valor añadido, están en función de la percepción de los consumidores y son a los que deben dirigirse las acciones comunicativas, pues son lo que diferencian unas empresas de otras. De este modo, en el caso que nos atañe, el entretenimiento es el valor añadido de PRISA, Antena, Mediaset y Vocento, mientras que la formación es otro rasgo distintivo pero de Intereconomía, Vocento y PRISA.

Otros atributos competitivos de los grupos de comunicación españoles están relacionados con: la cobertura, el sector, la especialización temática o la finalidad económica. De este modo, por Grupo, estos elementos diferenciadores son:

- En PRISA: el sector audiovisual y la internacionalización.

- En Antena 3: el sector audiovisual y la difusión nacional.

- En Mediaset: el sector audiovisual, la difusión nacional y la comercialización.

- En Mediapro: el contenido deportivo.

- En Vocento: los medios impresos, la difusión nacional con cabeceras tanto nacionales como regionales.

- En Unidad Editorial: los medios impresos y la información especializada.
- En Promecal: los medios impresos y la proximidad.

- En Intereconomía: la información con un tratamiento desde el pensamiento del $\mathrm{Hu}$ manismo Cristiano.

Además, el entorno competitivo ha propiciado una diferenciación basada en los valores corporativos y, más concretamente, en los códigos de conducta — son heterogéneos- y en la Responsabilidad Social —acciones solidarias, culturales, medioambientales, etc.-.

Por tanto, se puede afirmar que los grupos españoles buscan el posicionamiento mediante acciones comunicativas centradas en la diferenciación y la competencia. En este sentido, en Antena 3 para su agencia de publicidad Atres también se dirigen al consumidor.

En otras palabras, en los grupos multimedia analizados existe un equilibrio entre posicionamiento, diferenciación y marca, lo que equivale a decir que aplican el modelo $3 i$, o lo que es lo mismo el marketing 3.0.

\subsection{La aplicación del Marketing 2.0 y 3.0 en los portales de los grupos multimedia privados españoles}

Aparte de la marca, otra herramienta de comunicación es el portal de internet. Se trata de "una empresa de servicios que ofrece éstos a una determinada comunidad de internautas" (De Pablos y col., 2012:120), siendo sus funciones principales tanto informar como ser el punto de inicio de la navegación.

Como consecuencia de la competencia, los portales buscan diferenciarse con una oferta completa de servicios y con el desarrollo de contenidos de calidad para posicionarse estratégicamente, lo que conducirá a una consolidación de la marca. 
Existen dos tipos de portales, los horizontales — que ofrecen información de tipo genérico—y los verticales —que ofrecen servicios específicos para una comunidad determinada- Por la situación de saturación del mercado, los primeros están buscando una diferenciación, por lo que se están transformando en verticales (Villagra, 2002, 199-223).

Por otro lado, los verticales recurren a la profesionalización o a públicos muy específicos para diferenciarse y lograr así el afianzamiento de su marca.

Dentro de este tipo de portales verticales se encuentran los sitios web corporativos que se pueden definir como un catálogo electrónico con información actualizada de la empresa y sus productos y servicios. Su estructura depende de los objetivos fijados por la empresa.

Un ejemplo de esta clase de portales son los pertenecientes a los grupos multimedia privados españoles. Todos incluyen información sobre sus actividades y unidades de negocio, incluso algunos de ellos, como PRISA y Antena 3 tienen en la portada un enlace para dar a conocer su Responsabilidad Social Corporativa.

La presencia de las empresas en internet es importante, porque las webs corporativas son elementos de comunicación que no solamente facilitan numerosa información sobre sus productos y/o servicios, sino que también contribuyen a la creación de su imagen corporativa (Albendin, 2001:56).

Una manera de establecer la imagen corporativa es incorporando distintos perfiles para atender a sus públicos -clientes, proveedores, accionistas, etc.-- Cada uno de ellos accede a una web específica adecuada a sus intereses y necesidades. Por ejemplo, PRISA, Antena 3, Mediaset y Vocento poseen un perfil web destinado a sus accionistas e inversores; mientras que Unidad Editorial lo tiene para clientes y proveedores.

Concretamente, los clientes y proveedores de Unidad Editorial precisan de una clave para acceder a sus perfiles; en cambio, es abierto el acceso de accionistas e inversores en el resto de los grupos.

Por otro lado, normalmente, los portales de las empresas suelen incluir: información, comercialización e interactividad. Esta última está cobrando cada vez mayor importancia por el nacimiento de comunidades que ofrecen un espacio a sus usuarios para alojar sus páginas personales y otras que facilitan la interacción entre sus distintos miembros.

- Las ventajas que aporta la interactividad entre empresa y públicos son las siguientes:

- Amplía las fronteras de negocio.

- Permite establecer un servicio de atención y de fidelización de los clientes.

- Facilita numerosa información sobre los intereses y las necesidades de consumidores actuales y potenciales. Permite la elaboración de completas bases de datos.

- Retroalimentación.

Esta interactividad nos permite indicar que la comunicación "compartida" a través de las herramientas 2.0, explicada en párrafos anteriores, ha propiciado una transformación total de su cultura corporativa (Celaya, 2011:286-290).

En este sentido, la web 2.0 ha tenido un papel fundamental, ya que se ha convertido en un instrumento fundamental para que los usuarios participen en la actividad empresarial con sus opiniones y experiencias (McCracken, 2011:104107). Esta participación se ha puesto en primer plano con las redes sociales, las cuales se pueden clasificar en: redes profesionales _Linkedin, 
Xing, Viadeo...-, redes generalistas -Facebook, Tuenti, Google +, Myspace, etc.- y redes especializadas -Ediciona, Entrelectores, CinemaVIP...- (Celaya, 2011:109-276).

En este sentido, cabe decir que, de los grupos de comunicación españoles analizados, solo PRISA, Unidad Editorial y Vocento interactúan con sus públicos a través de redes sociales como Facebook y Twitter. De hecho, Vocento tiene un perfil llamado "Vocensocial" en el que se recopilan todas sus acciones interactivas.

Ante esta circunstancia es preciso matizar que si bien como grupo solo interactúan mediante las redes sociales las compañías que se acaban de mencionar, todos emplean esta herramienta en cada una de sus unidades de negocio.

Por otra parte, las redes sociales, aparte de ser una fuente de información muy fiable para conocer la imagen que tienen los públicos sobre los productos o servicios, dieron lugar a un nue- vo tipo de consumidores (McCraken, 2011:102107). Esto, a su vez, conllevó la aparición del marketing 2.0 y del marketing viral.

El marketing viral es el término elegido para referirse a las técnicas de marketing que intentan explotar las redes sociales y otros medios electrónicos para lograr imponer una marca o para mejorar su posicionamiento, mediante procesos de regeneración viral similares a la expansión de un virus informático. Este proceso se basa en el boca a boca producido por mecanismos electrónicos aprovechando las posibilidades abiertas por las redes sociales creadas en Internet y otros medios, como la telefonía móvil, para llegar rápidamente a una gran cantidad de personas.

Para concluir, según los visto sobre los sitios web corporativos de los grupos multimedia privados españoles, podemos afirmar que se aprecia una clara aplicación del marketing 2.0 y 3.0. 


\title{
Bibliografía
}

Albendin Moya, J. J. (2001). Marketing en Internet. Oviedo: Septem Ediciones.

Bassat, L. (2008). El libro rojo de las marcas (2 $2^{\mathrm{a}}$ ed.). Madrid: Debolsillo.

Capriotti, P. (2004). La imagen corporativa. In J. C. Losada Díaz (Ed.), Gestión de la Comunicación en las organizaciones (pp. 57-72). Barcelona: Ariel Comunicación.

Celaya, J. (2011). La empresa en la web 2.0. El impacto de las redes sociales y las nuevas formas de comunicación online en la estrategia empresarial. Barcelona: Gestión 2000.

De Pablos Heredero, C., López-Hermoso Agius, J. J., Martin-Romo Agius, S., \& Medina Salgado, S. (2012). Organización y transformación de los sistemas de información en la empresa. Madrid: ESIC.

Galán, J. (2008). Gestión Vectorial de la Imagen Corporativa. Razón y Palabra, 13(65).

Galindo García, Á., \& Fernández Olit, B. (2007). Responsabilidad Social Corporativa y Medios de Comunicación Social. Salamanca: Universidad Pontificia de Salamanca.
González Domínguez, F. J., \& Ganaza Vargas, J. D. (2008). Principios y fundamentos de gestión de empresas. Madrid: Ediciones Pirámide.

Kotler, P., Kartajaya, H., \& Setiawan, I. (2011). Marketing 3.0. Madrid: LID EDITORIAL.

McCracken, S. (2011). Marketing online para empresas. Barcelona: Servidoc.

Ramírez, F, Sánchez, M., \& Quintero, H. (2005). El papel de los valores en el desarrollo de la identidad corporativa. Negotium, 1.

San Nicolás, C. (2004). La marca. símbolo de consumo. In J. C. Losada Díaz (Ed.), Gestión de la Comunicación en las Organizaciones (pp. 351-363). Barcelona: Ariel Comunicación.

Villagra García, N. (2002). La presencia de los valores corporativos en internet un análisis aplicado al caso español. Doctora Memoria, Complutense, Madrid.

\section{Webgrafía}

\author{
www.prisa.com \\ www.grupoantena3.com \\ www.telecinco.es/inversores/es/ \\ www.mediapro.es/esp/index.php \\ www.unidadeditorial.com \\ www.intereconomiaformacion.com/ \\ www.promecal.es \\ www.vocento.com
}

